\title{
Kromatografiye Giriș, Yüksek Performanslı Sıvı Kromatografi Kullanımında Basit İpuçları
}

\author{
Introduction to Chromatography, Basic Working Tips for High Performance Liquid \\ Chromatography
}

Burcu ESER ${ }^{1-2}$, Aylin SEPICİ DİNÇEL ${ }^{2}$

ÖZ

Tıbbi Laboratuvardan ilaç sanayiine, gıdadan veterinerlik, ziraate; kimyadan çeşitli sanayii dallarına kadar çok geniş bir yelpazede kullanım alanı bulan kromatografi; ölçüm, ayrıştırma ve saflaştırma gibi değişik amaçlar için kullanılmaktadır. Farklı alanlarda ve çeşitli yöntemlerle kullanılan kromatografinin en önemli, etkin ve yaygın kullanım alanına sahip olanı ise Likit Kromatografi temeline dayanan yüksek performanslı sıv1 kromatografisi (HPLC) ve Siv1 Kromatografi-Kütle Spektrometri (LC-MS/MS) cihazlarıdır.

Kromatografi bir karışım içerisindeki bileşikleri birbirinden ayırmak ve maddeleri saflaştırmak için kullanılan bir yöntemdir ve ana amacı hedeflediğimiz numunenin ayrımının yapılması ve miktarının ölçülmesidir. Bu yöntem, çeşitli maddelerin, hareketli bir faz yardımıyla, sabit bir faz üzerinde, değişik hızlarla hareket etmeleri veya sürüklenmeleri esasına dayanır.

$\mathrm{Bu}$ derlemedeki amacımız kromatografiye giriş, kromatografik yöntemlere genel bir bakış, ardından HPLC ve LC-MS/MS cihazlarını tanıtmak ve kısa bir örnek ile metot geliștirme basamağı hakkında bilgi vermek, HPLC ve LC-MS/MS cihazlarıyla çalışma yaparken, metot geliştirirken araştırmacılara ve teknikerlere yol göstermektir.

Anahtar Kelimeler: Kromatografi, HPLC, LC-MS/MS

Aylin SEPICİ DİNÇEL (四)

${ }^{1}$ Sağllk Bilimleri Üniversitesi, Gülhane Sağllk Bilimleri Enstitüsü

${ }^{2}$ Gazi Üniversitesi Tip Fakültesi, Tibbi Biyokimya Anabilim Dalı

e-posta: asepicidincel@gmail.com

\begin{abstract}
Chromatography that finds usage in a wide range of fields from medical laboratories to the pharmaceutical industry, from food to veterinary medicine, agriculture, chemistry to different industrial branches; is used for various purposes such as measurement, separation and purification. The most important, effective and common use of chromatography by various methods for different fields is liquid chromatography which is based on high performance liquid chromatography (HPLC) and LC-MS/MS devices.

Chromatography is a method used to separate and purify the compounds in a mixture. The main aim of chromatography is separation and measurement of the amount of our target sample. This method is based on the principle of moving or drifting the various materials at different speeds on a stationary phase by a mobile phase.

The purpose of this article is to introduce an overview of chromatographic methods, followed by introduction of by descending to the basics of HPLC and to give brief information about a sample analysis and method development step. We hope that this article will shed light for researchers and technicians in developing methods and working at HPLC and LC-MS / MS instruments.
\end{abstract}

Keywords: Chromatography, HPLC, LC-MS/MS

\section{GİRİS}

Bu derleme, biyokimya bilim dalında yürütülen çalışmalarda sıklıkla kullanılan, kullanılma aşamalarında çok farklı sorunlarla karşılaşılan, buna karşın ileri teknoloji olarak kabul edilmeyen, rutin olarak kullanılmasının bilinmesi ve elde edilen sonuçların yorumlanabilmesi, öğrencilerin standart eğitimlerinde olması gereken bir konu olan kromatografik yöntemlerden yüksek performanslı sıv1 kromatografi (HPLC) cihazını kullanabilmeleri ve metot geliştirebilmeleri için hazırlanmıştır.

Kromatografi; ölçüm, ayrıştırma ve saflaştırma gibi değişik amaçlar için kullanılmaktadır. Sağlık, tarım, sanayi gibi 
birçok değişik alanda çeşitli kullanım yöntemleri olan kromatografinin en önemli, etkin ve yaygın olanı ise Likit Kromatografi temelli HPLC ve LC-MS/MS cihazlarıdır. Bu cihazlardan HPLC maddeleri kolondan çıkış zamanlarına (RT) göre analiz etmektedir. Siklıkla kullanılan diğer yöntem olan LC-MS/MS ise molekülleri hem kütle/yük oranlarına göre hem de kolondan çıkış zamanlarına göre analiz etmektedir.

$\mathrm{Bu}$ derlemede kromatografinin tanım, sinıflandırma, uygulama yöntemlerinden kısaca bahsettikten sonra sıklıkla laboratuvarlarda kullandığımız HPLC ve LC-MS/MS cihazlarınının tanıtımı, cihazların kullanım alanları, birbirleri ile karşılaştırmaları, yeni ölçüm metodlarının geliştirilmesi ve uygulanması hakkında bilgiler sunacağız. Bununla beraber metot geliştirmeye örnek olarak laboratuvarımızda geliştirdiğimiz bir deneme çalışması olan metalloproteinaz (MMP) ailesinden MMP-13 ve MMP-9 serum düzeylerinin HPLC ile ölçümü çalışmasını açıklayacağız.

\section{Kromatografi}

Kromatografi ilk olarak 1906'da Rus botanikçisi Mikhail Tswett tarafından bitki pigmentlerinin (klorofil) ayrımında kullanılmasından bu yana biyokimyasal moleküllerin tanımlanmasında ve ölçümünde güçlü bir teknik olarak kullanılmaktadır (7). Bu alandaki çalışmaları ile A.J.P. Martin ve R.L.M. Synge 1952 yılında, kütle spektrometresindeki çalışmaları nedeniyle de Fenn J. B. ve Tanaka K. 2002 yılında Kimya Dalında Nobel Bilim Ödülü aldılar. İlk modern cihaz ise 1965 yılında Yale Üniversitesi, Csaba Horvath tarafından geliştirildi.

Kromatografi terimi Yunanca kökenli olup "renk yazımı" ("khramoma" renk anlamına gelirken, "graphe" yazı anlamına gelmektedir) anlamındadır. Günümüzde kromatografi, ortak ve uygun bir çözücü ortamına konan bir karışımın içerdiği maddelerin fiziksel ve kimyasal özelliklerine göre çözünerek ayrıldığı ayırma işlemlerine toplu olarak verilen isimdir $(1,3)$.

Kromatografinin ana amacı hedeflediğimiz numunenin ayrımı ve miktarının ölçümüdür. Bu yöntem, çeşitli maddelerin, hareketlibir fazyardımıyla, sabit birfazüzerinde, değişik hızlarla hareket etmeleri veya sürüklenmeleri esasına dayanır. Çözücü mobildir yani hareketlidir ve incelenen karışımı sabit ortam boyunca taşır. Mobil ya da taşıyıcı faz değişik kromatografi tekniklerine göre sıvıdan gaza kadar, sabit faz da selüloz kağıdından kapiller cam tüplere kadar farklı bir dizi materyalden olabilmektedir. $\mathrm{Bu}$ karışım destek ortamı boyunca ilerlerken, molekül destek ortamındaki fonksiyonel gruplarla etkileşime girer.

\subsection{Kromatografinin temelinde bilinmesi gereken terimler}

Cihaz kullanımında ya da metot geliştirme aşamasında bu terimler ya da başka bir deyişle bu faktörler etkin rol oynamaktadır.

Mobil faz: Numuneyi, sabit faz (kolon) boyunca taşıyan, çeşitli fiziksel ve kimyasal özelliklere sahip çözücü karışımlarıdır. Kullanılacak olan mobil fazın seçiminde, analizi yapılacak numunenin bileşenlerinin özellikleri, kullanılacak sabit faz ve dedektörün özellikleri gibi parametrelere dikkat edilmelidir.

Sabit faz: Mobil faz içerisinde gelen numuneye ait bileşenlerin etkileşime girdikleri ve belirli ölçüde alıkonuldukları fazdır. Kromatografi tekniğinin çeşidine göre tasarlanmış, çok değişik materyallerden, çok farklı ölçülerde imal edilmiştir ve "kolon" olarak adlandırılırlar. Özellikle gaz ve sıvı kromatografileri için ticari boyutta çeşitli marka ve boyutta kolon üretimi yapılmaktadır.

Alıkonma: Mobil faz içerisinde gelen, analizi yapılacak numuneye ait bileşenlerin sabit faz ile etkileşime girerek, belirli oranda tutulması, yavaşlatılması ve böylece daha geç olarak sabit fazı terk etmesi olayıdır. Bu özellikten yola çıkılarak, belirli sabit analitik koşullar altında, her kimyasal madde için parmak izi niteliği taşıyan alıkonma zamanı (RT) tanımı türetilmiştir.

Sabit faz, mobil faz ve numunede yer alan maddeler arasındaki etkileşimin türü: "Yüzey tutunması veya adsorpsiyon" ile "çözünürlük” gibi kavramlar kromatografinin temelini oluştururlar (7).

\subsection{Kromatografinin farklı sınıflandırmaları}

Kromatografide, moleküllerin adsorpsiyon, dağılma ve değiştirme gibi özellikleri etkin rol oynar. Bu özelliklere göre de kromatografik yöntemler ayrılma mekanizmaları, uygulama biçimi, faz tiplerine göre farklı gruplarda toplanırlar (Tablo 1) $(1,2,3,6,10)$. 
Tablo 1: Kromatografik Yöntemlerin Sınıflandırılması

\begin{tabular}{|l|l|l|}
\hline Ayrılma Mekanizmalarına Göre Kromatografiler & Uygulama Biçimine Göre Kromatografiler & Faz Tiplerine Göre Kromatografiler \\
\hline Adsorpsiyon kromatografisi & $\begin{array}{l}\text { Düzlemsel kromatografi } \\
\text {-Kağıt kromatografisi } \\
\text { - İnce tabaka kromatografisi (TLC) }\end{array}$ & Sivı kromatografisi \\
\cline { 1 - 3 } Partisyon kromatografisi & \begin{tabular}{l} 
Kolon kromatografisi \\
-Gaz kromatografisi (GC) \\
İyon değiştirme kromatografisi \\
\cline { 2 - 3 } Jel filtrasyonatografisi
\end{tabular} & Siv1-Sivı kromatografisi \\
\hline
\end{tabular}

Kromatografik temelli yöntemlerin kullanılan mobil ve sabit faz gibi değişik faktörlere göre değişik sınıflandırmaları olduğu görülmektedir.

Şimdi laboratuvarlarımızda sıklıkla kullanmakta olduğumuz sivı kromatografi temelli HPLC ve LC-MS/MS cihazlarından kısaca bahsedelim.

\section{Yüksek Performanslı Sıvı Kromatografisi (HPLC)}

\subsection{HPLC Cihazı ile Çalışma Basamakları:}

1. Test edilecek biyomolekülün uygun bir çözücüde çözünmesi: Protein, peptit ya da diğer test edilecek olan moleküller organik ya da uygun bir çözücü kullanılarak çözülür.

2. Numunedeki bileşenlerin ayrımı: Bileşenlerin ayrımı sabit faz olarak nitelendirdiğimiz kolonda gerçekleşir. Çözünen karışım kolona enjekte edilir. Kolon boyunca bu karışım ve mobil fazdan oluşan sıvının hareket etmesi için bir basınç uygulanır. Bu basınçla birlikte farklı bileşenler, kolonda farklı hızlarda ilerlerler. Böylece bileșenler çıkışa farklı zamanlarda ulaşır.

3. Ayrılan bileşenlerin ve miktarlarının tayin edilmesi: Bileşenler ayrıldıktan sonra miktarlarının tayini için detektörlerden faydalanılır. Bunun için numunelerin özelliklerine göre UV, floresans, iletkenlik, kütle gibi farklı detektörler seçilebilir.

4. Kromatogramların değerlendirilmesi: Detektörden elde edilen kromatogramlar günümüzde değişik bilgisayar programları yardımıyla rahatça yorumlanabilmektedir (4).

\subsection{HPLC Cihazına Genel Bakış:}

Genel olarak 8 kısımdan oluşur; Mobil faz (çözücü) şişeleri, degasser, pompa, enjektör, kolon firını, kolon, dedektör, kaydedici, bu kısımlardan bazıları çalışılacak numuneye ve cihaz marka, modeline göre değişiklik gösterebilir.

2.2.1. Mobil faz (çözücü) șişeleri: Genel olarak bir HPLC cihazında bir veya daha çok cam veya paslanmaz çelik kaplar bulunabilir. Çalışmada sulu tamponlardan hidrokarbonlara kadar farklı polaritede çözücüler kullanılabildiği için bu kapların kalitesi önemlidir. Ayrıca kullanılan bu çözeltilerin saf olması gereklidir. $\mathrm{Bu}$ durum kolonu veya numuneyi etkileyerek hatalara sebep olabilir.

2.2.2. Degasser: Mobil faz içerisinde bulunan eriyik gazların giderilmesi için kullanılan bir sistemdir. Tüm solventlerin gazının alınması gereklidir. Mobil fazda hava kabarcıklarının bulunması pompa ve kolonda problemlere yol açabilmektedir. Örneğin; kolonda kabarcık oluşması pik genişlemesine veya RT’nın kaymasına yol açabilir. Gazın alınması farklı şekillerde gerçekleştirilebilir; solventlerin 1sıtılması, karıştırarak vakuma maruz bırakma, ultra sonifikasyon veya solvent şişesine helyum gazı verilmesidir. Ancak gelişen teknoloji ile beraber cihazda standart olarak bulunan bir modül haline gelmiştir.

2.2.3. Pompa: HPLC pompas1, sivi kromatografi sisteminin en önemli kısımlarından bir tanesidir. Sistemde; numune ve fazımızın enjektör, kolon ve dedektör boyunca sürekli sabit akışını sağlayan kısımdır. Pompanın görevi sıvının sistem içerisinde dolaşımını sağlamaktır. Dakikada akan $\mathrm{mL}$ cinsinden gösterilir. Yüksek basınç altında çalışabilmesi, basınç dalgalanmasının düşük olması, akış doğruluğu ve tekrarlanabilirliği, kendi üzerinden kumanda edilebilme olanağı bir pompa sisteminde olması gereken temel özelliklerdir (2).

HPLC donanımında yer alan pompalama sistemleri, akış hızına (mikrobore, standart bore ve preperatif pompa sistemleri), pompanın yapımında kullanılan malzemeye (metalik, ametalik), pompanın mobil fazı iletme mekanizmasına (şırınga tipi, piston pompalar) ve tipine (izokratik/tek kanallı, binary/ikili, quaternary/ gradyen 4 kanallı pompa sistemleri) göre değişik şekillerde sinıflandırılabilir. 
Burada izokratik ve gradyen sistem pompaları öne çıkmaktadır. Çalışmalarda moleküllerin ayrımı ve metot geliştirmede önemlidir.

Bir deney sırasında pompa, değişmeyen sabit bir akış sağlıyorsa bu sisteme izokratik sistem denir, basit ayrımlar için uygundur. Gradyan sistemde hareketli faz bileşimi zamanla değişim gösterir. Kompleks karışımların ayrımı için ve bilinmeyen karışımlarda metot geliştirmek için tercih edilir $(2,4)$.

2.2.4. Enjektör: HPLC sistemini oluşturan kısımlardan biri olan enjektör, numunenin sabit faz (kolon) öncesinde mobil faza enjekte edilmesi için kullanılır. Elle kumanda edilen manuel ve bilgisayar kumandalı oto-enjektörler olmak üzere 2 çeşidi bulunmaktadır.

Günümüzde artık Oto-enjektör ünitelerinde soğutma, 1sitma, seyreltme ve karıştırma gibi özellikler de vardır.

2.2.5. Kolon Fırını: Çalışmanın kalitesi açısından kolonun tutulduğu ortamın sabit bir 1sıda olması gerekmektedir. Bunun için kolon firını HPLC cihazlarında önem arz eder. Hava sirkülasyonlu ve blok ssitıcilı olmak üzere iki türü vardır.

2.2.6. Kolon: HPLC donanımının temel yapı taşlarından birisi olan kolon, karmaşık örneklerde bileşenlerin birbirinden iyi çözünürlükle ayırımından sorumlu sabit fazdir.

Kolon iç yüzeyinde kullanılan malzemenin kimyasal ve fiziksel özellikleri çok çeşitli olup, kullanılacak mobil fazın ve uygulanacak HPLC metodunun özelliklerine ve analizi yapılacak örneğin bilinen kimyasal ve fiziksel özelliklerine göre seçilmelidir.

Birçok analitik kolonun iç çapı 2-5 mm aralığında değişmektedir. Kolon iç çapı arttıkça akış hızı ve iç doldurma hacmi artmakta fakat oluşacak piklerin çözünürlüğü dolayısıyla duyarlılık azalmaktadır.

Kolonların uzunluğu çok çeşitli olup genellikle 30-300 mm aralığında değişmektedir. Kolon uzunluğu arttıkça örnek bileşenlerinin ayırımı daha iyi olmakta fakat analiz süresi uzadığı için daha fazla mobil faz harcanmaktadır. Analizler için doğru kolon seçimini yapmak çok önemlidir.

Kolon boyutlarının tanımlanmasına uluslararası standartlar getirilmiştir. Buna göre önce $\mathrm{mm}$ cinsinden uzunluk ve çap yazılmakta, bunu firma adı, sabit faz türü, Ångström türünden poroz yüzey çapı ve $\mathrm{mm}$ cinsinden partikül büyüklüğü izlemektedir (Şekil 1) $(10,11,12)$.

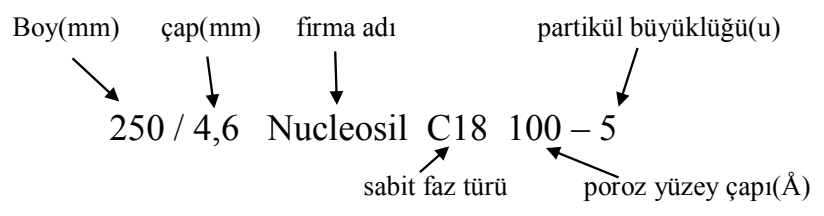

Şekil 1: Örnek bir kolon tanımlanması

Kolon seçimi esnasında kolon dolgu maddeleri ve karakteristikleri, partikül boyutu ve şekli, por çapı, fonksiyonel grupların bağlanma şekilleri, karbon yükü, endcapped özelliği, silika saflığı gibi bazı terim ve parametreleri çok sık duyacağız ve çalışmamızı direkt etkileyecektir.

HPLC'de kullanılan kolon ile mobil faz ve bunların etkileşimleri gibi bazı özellikler dikkate alınarak farklı ayrım teknikleri geliştirilmiştir. Bunlar arasında Normal Faz (Normal Phase; NP), Ters Faz (Reverse Phase; RP), Ters Faz İyon Çifti (Reverse Phase Ion Pairing; IP), İyon Değişim (Ion Exchange; IC), Boyut Eleme (Size Exclution; SEC (GPC/GFC)) ve Kiral Ayrmm (Chiral Separation) tekniklerini sayabiliriz (2).

2.2.7. Dedektör: Kolondan çıkan bileşenleri görebilmemizi, bunların ayrım ve miktarlarını belirlememizi sağlar. Dedektörden geçen maddeler bir kaydedici yardımıyla kaydedilerek, zamana karşı dedektör cevabına ait bir grafik oluştururlar ve buna da kromatogram denir.

Ultraviole/Görünür Bölge Dedektörü (Ultraviolet/Visible Dedector-UV/VIS), Fotodiyot Array Dedektörü (Photodiode array dedector-DAD), Floresans Dedektörü (Fluorescence dedector-FLD), İletkenlik Dedektörü (Conductivity dedector-CDD), Refraktif İndeks Dedektörü (Refreactive index dedector-RID), Elektrokimyasal Dedektör (Electrochemical dedector-ECD), Kütle Dedektörü (Mass dedector-MS) gibi çeşitli dedektörler geliştirilmiştir (3, 4, $11)$.

Yapacağımız çalışmaya veya analizini yapmak istediğimiz numunenin özelliklerine uygun bir dedektör seçmeliyiz.

\section{Sıvı Kromatografi-Kütle Spektrometresi (LC- MS/MS)}

Sivı kromatografi temeline dayanan bir yöntem ve cihazdır. Kullanılan kütle dedektörünün sağladığı çalışma kolaylığı, keskinlik gibi etkenler nedeniyle laboratuvarlarda ekstra önem kazanmıştır. Çalışmalarda metot yazarken HPLC-UV, 
HPLC-FLD, HPLC-MS şeklinde gösterimlere rastlanabilir. Aslında LC-MS/MS cihazını HPLC cihazının bir alt türü gibi tanımlayabiliriz. Fakat kütle dedektörünün yüksek özellikleri sayesinde farklı bir yöntem veya cihaz olarak anılmaktadır.

Kütle spektrometreleri manyetik veya elektriksel bir alanda hareket eden yüklü partikülleri kütle/yük $(\mathrm{m} / \mathrm{z})$ oranlarına göre diğer yüklü partiküllerden ayırt ederek ölçme esasına göre çalışan cihazlardır $(8,9,10)$.

Kütle dedektörü iyon kaynağı, kütle analizörü ve iyon dedektör sistemi olmak üzere 3 kısımdan oluşur.

İyon Kaynağı: Numunenin iyonlaştırılarak cihaza gönderildiği kısımdır. Analizi yapılacak numunenin özelliklerine göre ESI (Electrospray Ionization) veya APCI (Atmospheric Pressure Chemical Ionization) iyonizasyon teknikleri kullanılabilir. Genel olarak aminler, peptidler ve proteinler gibi polar bileşikler ESI tekniği, steroidler gibi apolar bileşikler ise APCI tekniği ile analiz edilir $(8,9)$.

Kütle Analizörü: İyon kaynağından gelen iyonlar, kuadropoller sayesinde değişen elektromanyetik bir alana tabi tutularak m/z (kütle/yük) oranlarına göre ayrılırlar (8, 9).

MS İyon Dedektör Sistemi: MS dedektörü yüksek duyarlılığa sahip, pozitif ve negatif iyon modlarında çalışabilen iyonları kütle ve yüklerine göre analiz edebilen bir sistemdir $(8,9)$.

Kütle Spektrometresi, bilinmeyen bileşiklerin tanımlanması, organik ve inorganik moleküllerin yapısal özelliklerinin belirlenmesi gibi her türlü bilinen bileşiğin kantitatif analizinin "yüksek duyarlılık ve özgüllükte" ölçebildiği bir tekniktir. Molekülleri kütle/yük oranınına $(\mathrm{m} / \mathrm{z})$ göre ayrıştırır ve ölçer (8). Bunun için önce moleküller iyonlara (elektriksel olarak + ya da - yüklü hale) dönüştürülür. Ardından gaz fazına geçirilerek cihaza gönderilir. LC-MS de her molekül için bir retansiyon zamanı ve bir m/z değeri vardır. Aynı m/z oranına sahip pek çok molekül mevcut olmasına karşın aynı parçalanma iyonlarına sahip molekül sayısı doğada 1/10000 dür.

LC-MS/MS çok düşük konsantrasyonlarda bile maddenin miktar tayininin yapılabilmesini mümkün kılmaktadır. Sonuçların doğrulanmasına da gerek duyulmamaktadır. MS/MS, kantitatif uygulamalar için yüksek bir duyarlılık ve kesinlik sağlar.

\section{HPLC ve LC-MS/MS cihazlarının kullanım alanları ve performanslarının karşılaştırılması}

Buraya kadar kromatografik yöntem ve cihazları tanımaya çalıştık. HPLC ve LCMS/MS cihazlarının bize kazandırdıkları ve kullanım alanlarına da kısaca değinelim.

\subsection{HPLC'nin Kullanım Alanları}

Çok yaygın kullanım alanı bulunan bu teknik ile yapılan analizleri yedi başlık altında topladık. Bunlar; (a) ilaç analizleri (antibiyotikler, sedatifler, steroitler, analjezikler), (b) biyokimyasal analizler (aminoasitler, proteinler, karbonhidratlar, lipitler, hormonlar, vitaminler, VMA, metanefrin, 5HİAA, katakolaminler, ketosteroidler, Porfirin, Homosistein, HbA1C), (c) gida analizleri (antioksidanlar, alfatoksinler, suni tatlandırıcılar, gıda katkı maddeleri, hormon ve pestisit kalıntı analizleri, su analizleri), (d) adli tıp, toksikoloji (uyuşturucu ilaçlar, narkotikler, zehirler), (e) klinik biyokimya (Safra asitleri, üre ekstraktları, ilaç metabolitleri), (f) Gıda ve çevre kirleticileri (Pestisitler, herbisitler, fenoller), (g) Endüstriyel analizler (Polimerler, boyalar, yüzey aktif maddeler, çok halkalı aromatikler, petro kimya uygulamaları) $(12,13)$.

\subsection{LC-MS/MS Kullanım Alanları}

Klinik Uygulamalar; Yeni doğan taramaları, yağ asidi oksidasyon defektleri, organik asidemiler, amino asit metabolizması bozuklukları, üre siklusu enzim defektleri gibi birçok metabolik hastalığa aynı anda ve çok kısa sürede tanı koymak mümkündür. Lizozomal depo hastalıkları; (Mukopolisakkaridozlar (MPS), steroid hormonlar; E1, E2, progesteron, testesteron, kortizol (serum, idrar ve tükrük), aldosteron, androstenedion, kortizol, kortizon, 11-deoksikortizol, 21-deoksikortizol, 17-OHP, DHEA, DHEAS), D Vitamini; D2, D3, 3-epi izomerleri, vitaminler, insülin, T3, hemoglobin analizleri, karbohidratlar, karmaşık matrislerde bulunan eser seviyedeki analitlerin hassas miktar tayini, doku, kan gibi biyolojik örneklerde ilaç ve metabolitlerinin ölçümü, oksidatif stres biyobelirteçlerinin kantitatif analizi (SOD, katalaz, MDA), tiyol biyobelirteçlerin ölçümü (homosistein), 8-OHdG ve ilişkili DNA biyobelirteçleri ölçümü, DNA baz hasarı ölçümü (8OHdG - 8-hidroksi-2`deoksiguanozin).

Biyoteknoloji : Protein, peptit ve oligonükleotidler

Adli Tıp, Toksikoloji: Uyuşturucu ilaçlar, narkotikler, zehirler 
Farmasötik Uygulamalar: Farmakokinetik, İlaç metabolizması, İlaç geliştirme, İlaç seviyeleri

Çevre, gıda analizleri: Gıda numunelerinde pestisit ve metabolitlerinin, hormon ve metabolitlerinin, aflatoksinmikotoksin analizleri vb., su analizleri $(8,9,13)$.

\subsection{HPLC ve LC-MS/MS cihazlarının performans karşılaştırmaları}

HPLC cihazının çalışmalarımıza katkıları eş zamanlı analiz, doğruluk, yüksek hassasiyet (ppm-ppb), küçük enjeksiyon hacmi (1-100 $\mu 1)$, geniş uygulama sahası, zor olmayan analiz koşulları ve çok iyi tekrarlanabilirlik $(10,11,12$, 13) olarak sıralanabilir. Yukarıda da bahsettiğimiz üzere LC-MS/MS cihazında kullanılan kütle dedektörü sayesinde HPLC'de ölçemediğimiz ya da ayrımını yapamadığımız birçok numne LC-MS/MS'de ölçülebilmektedir. Ayrıca yüksek seçicilik, özgünlük ve az miktarda reaktif gerekliliği gibi avantajları sayesinde özel olarak tercih edilmektedir. Ek olarak geniş analitik ölçüm aralığı, aynı anda birçok analitin ölçülebilmesi, eser miktardaki maddelerin tespiti ve doğrulama metodu olarak tavsiye edilebilmesi de avantajları arasında sayılabilir. HPLC ise kullanımı ve uygulaması kolay ve daha az maaliyetli olması gibi avantajları sayesinde cihazın bakımı ve maliyet yüksekliği, yüksek deneyimli personel gerekliliği, analizin kompleksliği, referans metot yokluğu, otomasyon uyumsuzluğu gibi zorlukları olan LC-MS/MS'e karşı tercih sebebidir. Bunlara ek olarak LC-MS/MS düşük dedeksiyon limiti ve parmak izi hassasiyetinde ve doğruluğunda sonuçlar vermesi sayesinde laboratuvarlarda (özellikle adli tıp ve toksikoloji alanlarında) altın standart yöntem olarak kabul edilmektedir.

\section{HPLC'de metot geliştirme}

HPLC ile metot geliştirmede öncelikle numune ve aradığımız biyomolekülün yapısını, fiziksel ve kimyasal özelliklerini belirlememiz gerekmektedir. Daha sonra bu özelliklere uygun mobil faz, kolon, yöntem vb. seçimleri yapılır. Seçimleri yaparken çalışma esnasında yakın özellik ve etkinlikte olan kolon boyutları, mobil faz içeriği gibi birçok değişken karşımıza çıkacaktır. En iyi sonuçları elde edebilmek için tüm bu değişkenleri tek tek ele alıp, ayrı ayrı çalışarak değerlendirmemiz gerekir. Bu süreç bazen çok uzun zaman almaktadır. Yapacağımız çalışma ile ilgili iyi bir kaynak taraması, referans metot ve makale araştırması mutlaka gerekmektedir. Burada ilaç ve cihaz firmalarının ya da resmi kurum (Ör: FDA) ve bilim kuruluşlarının yayınladığı broşür, internet sitesi gibi kaynaklardan da faydalanabiliriz $(4,5,10,11,12,13,14)$.

HPLC ile analiz yöntemi geliştirilmesine örnek bir çalışmamızda ise geniş faaliyet yelpazesi ve ifade alanlarına ve kompleks bir yapıya sahip metalloproteinaz (MMP) ailesinden MMP-13 ve MMP-9 düzeyleri ele alınarak öncelikle en yaygın olarak kullanılanı ELIZZA yöntemi ile belli hasta serumlarında MMP-13 ve MMP-9 düzeyleri tespit edildi. Ancak bu yöntemin hassasiyet ve özgüllük ile ilgili dezavantajları düşünülerek laboratuvarlarda yaygın olarak kullanılan ve hassaslığı ve yaptığı doğru ölçümlerle bilinen HPLC cihazı ve yöntemi ile örnekler çalışıldı. Yapılan literatür taramasında MMP'lerin HPLC'de ölçümüne dair referans bir metot bulunamamıştır $(17,18)$. ELIZZA değerleri bilinen hasta sonuçları HPLC çalışmasından elde edilen sonuçlarla karşılaştırıldı. Literatür taramasının ardından MMP için HPLC'de bir ölçüm yöntemi geliştirme denemesi yaptık $(19,20,21)$. Yöntemde kullanılan cihazlar; CBM20A Sistem Kontrol Ünitesi, DGU-20A On-line Degaz Ünitesi, LC-20AT Pompa, SIL-20AC Oto Örnekleyici, CTO-20A Kolon Firın, SPD-M20A Photo-diode Array (PDA) dedektör modüllerinden oluşan Shimadzu HPLC sistemidir. Kullanılan kimyasal maddeler HPLC grade idi. Çalışmada İntersil ODS3 $5 * 4,6 * 150 \mathrm{~mm}$ analitik kolon kullanıldı. İzokratik modda çalışıldı. Mobil faz olarak $\% 60$ Asetonitril, \%40 Distile su ve \%0,01 Trifloroasetik asit karışımı kullanıldı. MMP standartları metanolde dilüe edilerek kullanıldı. Örnek serumlar ise perklorik asit ile ekstrakte edilerek cihaza enjekte edildi. PDA dedektör ile yapılan dalga boyu taramasında en yüksek pikin $205 \mathrm{~nm}$ ye ait olduğu gözlendi. MMP-13 ve MMP-9 standartları metanol ile çözülerek 1000 ve $500 \mathrm{ng} / \mathrm{ml}$ 'ye seyreltildi. Standartların cihaza ayrı enjeksiyonundan sonra elde edilen komatogramlar üstüste çakıştırılarak piklerin uyumluluğu gösterildi. Aynı zamanda konsantrasyonlar arasındaki fark ile uyumlu kromatogramlar elde edildi. Standart çalışmalarında elde ettiğimiz pikleri örnek serumlarda da elde edip edemeyeceğimizi araştırmak amacıyla bir örnek serum, aynı örnek seruma MMP-13 ve MMP-9 standartlarını ayrı ayrı ve beraber ekleyerek deneme çalışmaları yaptık. MMP miktarlarının normal sağlıklı insan serumlarında çok düşük seviyede olduğu birçok literatürde bahsedilmiştir. Sadece örnek serumun kullanıldığı çalışmada herhangi bir pik elde edilememiştir. Elde edilen kromatogramları incelediğimizde MMP-13 ve MMP-9 standartlarının seruma ayrı ayrı eklenmesiyle yapılan ölçümlerde piklerin retansiyon zamanlarında bir fark gösterilememiştir. $\mathrm{Bu}$ 
durum elde edilen piklerin total MMP'ye ait olduğu durumunu düşünmemizi sağlamıştır. Ardından MMP-13 ve MMP-9 standartlarının birlikte seruma eklenerek yapıldığ 1 çalışmada elde ettiğimiz pikler de bu sonucu doğrular niteliktedir.

\section{SONUÇ}

Bu derlemede laboratuvarlarda sıklıkla kullanılan ve daha da gelişerek kullanılmaya devam edilecek olan HPLC ve LC-MS/MS cihazlarının özelliklerini tanımladık. Bu cihazların iyi bir şekilde tanınması gerek rutin çalışmalarda, gerekse geliştirilecek yeni tanı yöntemlerinde büyük kolaylıklar sağlayacaktır.

Teşekkür Bilgisi: $\mathrm{Bu}$ derleme eğitim materyalinin hazırlanmasında ve sunulan verilerin çalışılmasında sağlanan maddi destek Gazi Üniversitesi Bilimsel Araştırma Projeleri Birimi tarafindan 01/2017-35 kodu ile desteklenen proje ile gerçekleştirilmiştir.

\section{KAYNAKLAR}

1. Yıldız A, Genç Ö, Bektaş S. Enstrümental Analiz Yöntemleri. Hacettepe Üniversitesi Yayınları. Ankara. 1997.

2. Burtis CA, Ashwood RA, Çeviri Editörü: Prof.Dr.Diler Aslan. Tietz Klinik Kimyada Temel İlkeler, 5.Baskıdan Çeviri (Palme). 2007

3. Skoog DA, Holler FJ, Nieman TA. Çeviri Editörleri:Kılıç E, Yılmaz H. Enstrümantal Analiz İlkeleri. 6. Baskıdan çeviri. Bilim yayıncılık, Ankara

4. Pathy KS ,Murthy YLN, Sunithasarma, Ramaiah A. Basıc Skılls Trainıng Guide - HPLC method development and validation - an overview

5. Pathy KS. How to Start Analytical Method Development

6. Frrat Üniversitesi Fen Fakültesi Kimya Bölümü. Enstrumental Analiz Laboratuvarı Deney Föyü. 2013

7. Prof. Dr. Ulvi Reha Fidanci. Kromatografi. Ankara Üniversitesi Veteriner Fakültesi. http://ulvireha.fidanci.org/ kromatografi/

8. İşlekel H. LC-Tandem MS-MRM Temel Araştırma ve Klinik Laboratuvarda Kullanım. Dokuz Eylül Üniversitesi Tip
Fakültesi. 2011 (http://www.turkbiyokimyadernegi.org.tr/ dosyalar/belgeler/kongre/huray-islekel.pdf)

9. Biberoğlu G. Kütle Spektrometresi ve Tip Alanında Kullanımı. T Klin Tıp Bilimleri 2003, 23:491-498

10. Aguilar, M.I. (2004). HPLC of Peptides and Proteins Methods and Protocols. Totowa, New Jersey: Humana Press Inc.

11. Snyder, L.R., Kirkland, J.J., Glajch, J.L. (2012). Practical HPLC Method Development (Second Edition). Canada: John Wiley \& Sons, Inc.

12. Boyer R. Biochemistry Laboratory: Modern Theory and Techniques. Benjamin Cummings, San Francisco, A.B.D. 2009

13. Gault V. A. and McClenaghan, N. H. Understanding Bioanalytical Chemistry. Principles and Applications. WileyBlacwell, Fabulous Printers Pte. Ltd., Singapore, 2009

14. Reed R., Holmes D., Weyers J., Jones A. Practical Skills in Biomolecular Sciences. Second Edition, Pearson Education, 2003.

15. Boyer R. Concepts and Skills in the Biochemistry/Molecular Biology Lab. Biochemistry and Molecular Biology Education 31(2): 102-105, 2003

16. Büyüköztürk, Ş., Kılıç Çakmak E., Akgün, Ö. E., Karadeniz, Ş., ve Demirel, F.. Bilimsel Araştırma Yöntemleri, Ankara, Pegem A Yayınc1lık, 2008.

17. Clark, I.M. (2001). Matrix Metalloproteinase Protocols. Totowa, New Jersey: Humana Press Inc.

18. Clark, I.M. (2010). Matrix Metalloproteinase Protocols (Second Edition). London: Springer Science+Business Media, LLC, Humana Press Inc.

19. Fernandez-Patron, C., Zouki, C., Whittal, R.M., Chan, J.S., Davidge, S.T., Filep, J. (2002). Methods for Analysis of Matrix Metalloproteinase Regulation of NeutrophilEndothelial Cell Adhesion. Biol Proced Online, Oct 28;4:3848.

20. Kotnik P, Krajnc MK, Pahor A, Finšgar M, KnezŽ. HPLC-MS/ MS method optimisation for matrix metalloproteinase 3 and matrix metalloproteinase 9 determination in human blood serum using target analysis. J Pharm Biomed Anal. 2018 Feb 20;150:137-143.

21. Wang Y, Zagorevski DW, Lennartz MR, Loegering DJ, Stenken JA. Detection of in vivo Matrix Metalloproteinase Activity using Microdialysis Sampling and Liquid Chromatography-Mass Spectrometry. Anal Chem. 2009 Dec 15; 81(24): 9961-9971. 